\title{
Renúncia fiscal (gasto tributário) em saúde: repercussões sobre o financiamento do SUS
}

\author{
Fiscal waiver (tax spending) in health: effects on financing of the SUS
}

Áquilas Mendes' ${ }^{1}$ José Alexandre Buso Weiller²

RESUMO No contexto do capitalismo financeirizado, marcado por uma transferência direta de direitos à saúde para o mercado, as renúncias fiscais (gastos tributários) se apresentam como engrenagens que ampliam o poder das instituições privadas no setor saúde, prejudicando o financiamento do Sistema Único de Saúde. É notável o arcabouço legal desenvolvido no Brasil, que assegura a constante ampliação das renúncias fiscais, principalmente nesse setor, contribuindo para a ampliação da cobertura de planos de saúde. Este artigo destaca a efetiva transformação do direito à saúde em garantia de consumo de produtos e serviços, denotando o claro processo de mercantilização que essa política vem sofrendo.

PALAVRAS-CHAVE Renúncia fiscal; Gasto tributário em saúde; Financiamento do SUS.

ABSTRACT In the context of financial capitalism, marked by a direct transfer of rights to health to market, fiscal waivers (tax expenditures) present as gears that extend the power of private institutions in the health sector, damaging Brazilian Unified Health System financing. It is remarkable the legal framework developed in Brazil, that provides permanent extension of tax waivers, especially in this sector, contributing to increasing coverage of health plans. This article highlights the effective transformation of the right to health in guarantee of consumption of products and services, denoting the clear process of commodification that this policy has been suffering.

KEYWORDS Fiscal waiver; Health tax expenditure; SUS financing.

1 Universidade de São Paulo (USP), Faculdade de Saúde Pública - São Paulo (SP), Brasil. Pontifícia Universidade Católica de São Paulo (PUCSP), Departamento de Economia - São Paulo (SP), Brasil.

aquilasn@uol.com.br

2 Universidade de São Paulo (USP), Faculdade de Saúde Pública - São Paulo (SP), Brasil.

jose.alexandre.bw@gmail.com 
1 A temática dos problemas do financiamento da saúde pública, ao longo dos vinte e sete anos de existência do SUS, está apoiada na discussão realizada por Mendes (2012). Esse autor também discute a força predominante do capital portador de juros no capitalismo contemporâneo, baseado na descrição desse capital, conforme tratado na seção quinta do Livro III de 'O Capital', de Marx.

2 Dados extraídos do Banco Central do Brasil <www.bcb. gov.br/> e do Ministério da Saúde <http://portalsaude. saude.gov.br/>. Acessos em: out. 2014.

3 Dados da Organização Mundial da Saúde, de 2009 (WHO, 2012).

\section{Introdução}

O objetivo deste artigo é analisar a dimensão da renúncia fiscal (gasto tributário) na saúde, no âmbito da União, especialmente entre 2003 e 2012, identificando-a como um dos obstáculos para assegurar o financiamento do direito universal à saúde.

Os embates por recursos financeiros para assegurar a política pública universal da saúde sempre foram uma constante desde a criação do Sistema Único de Saúde (SUS), em 1988. A história de tensões no financiamento desse sistema não deixou de ser intensa antes e durante os anos 2000, após a aprovação da Emenda Constitucional (EC) $\mathrm{n}^{\mathrm{o}}$ 29/2000. Ao mesmo tempo, nesse período, a fragilidade do financiamento foi percebida no crescimento da renúncia fiscal decorrente da dedução dos gastos com planos de saúde e símiles no Imposto de Renda e das concessões fiscais às entidades privadas sem fins lucrativos (hospitais) e à indústria químico-farmacêutica, enfraquecendo a capacidade de arrecadação do Estado brasileiro e convertendo-se no que se convencionou denominar gasto tributário. Essa denominação apoia-se em Alvarenga (2012) e será discutida na segunda parte deste artigo.

O tema da renúncia fiscal (gasto tributário) em saúde não tem sido tratado de forma considerada no âmbito da discussão sobre a problemática do financiamento do SUS. São poucos os estudos que se referem a esse tema. Entre eles, destacam-se: Sayd (2003); Dain et al. (2002); Ocké-Reis e Santos (2011); Ocké-Reis (2013).

Verifica-se, ao longo de vinte e sete anos de existência do SUS, um quadro complicado de disponibilidade de recursos e de fontes inseguras, o que se poderia designar como 'tempos turbulentos' do financiamento do SUS'. Iniciamos a década de 2010 sem resolver esses grandes conflitos, na medida em que a Lei $n^{\circ}$ 141/2012 (regulamentação da EC no 29/2000) não assegurou novos recursos financeiros para a saúde universal, especialmente por parte da União, e, ainda, nada foi realizado com relação ao estabelecimento de uma política de renúncia fiscal para o setor privado, sem prejuízo dos recursos do Estado, especialmente direcionados às políticas de direitos sociais, como a saúde.

A compreensão dos impasses do financiamento do SUS, ao longo de sua existência, somente é possível se articularmos dois planos de análise: de um lado, destacam-se as consequências perversas da política macroeconômica restritiva, implementada durante os dois governos Lula, dando prosseguimento ao que era feito por Fernando Henrique Cardoso, com o objetivo central de assegurar o cumprimento de metas de inflação e a obtenção de elevados superávits primários, resultando em constante pressão para que o gasto público fosse diminuído, o que, no SUS, assumiu a forma de contingenciamento. De outro lado, evidenciam-se os efeitos da dinâmica do movimento do capital contemporâneo, que tem sob comando o capital portador de juros (capital financeiro) e sua insaciabilidade pela apropriação dos recursos do fundo público da seguridade social e da saúde ${ }^{2}$. Para se ter uma dimensão da interpenetração do capital financeiro no orçamento público federal, em 2012, o gasto com juros e encargos da dívida pública representou R $\$ 126,3$ bilhões, enquanto o gasto do Ministério da Saúde foi 37\% menor.

Com a vinculação de recursos para a saúde pública, a partir da $\mathrm{EC} \mathrm{n}^{\circ} 29 / 2000$, permitiu-se que o gasto SUS aumentasse de $2,89 \%$ do PIB, em 2000, para 3,8\% do PIB, em 2011 (sendo 1,7\% da União, 1,1\% dos municípios e $1,0 \%$ dos estados), o que é ainda insuficiente para torná-lo universal e garantir o atendimento integral (SERVO ET AL., 2011). No entanto, O gasto público brasileiro é baixo em relação ao dos demais países que possuem um sistema público universal. Para que o Brasil atingisse o nível desses países, precisaria dobrar a participação do SUS com relação ao PIB, a fim de alcançar equiparação com a média de alguns países desenvolvidos (Reino Unido, Canadá, França e Espanha), isto é, 8,3\% ${ }^{3}$. 
A constatação do reduzido gasto público deve também ser entendida a partir do incentivo concedido pelo governo federal à saúde privada, na forma de redução de Imposto de Renda a pagar, da pessoa física ou jurídica, aplicada sobre despesas com plano de saúde e/ou médicas e similares. Além disso, há de se acrescentar as renúncias fiscais que experimentam as entidades sem fins lucrativos e a indústria químico-farmacêutica.

Este artigo está estruturado em três partes. A primeira caracteriza, de maneira breve, os problemas do financiamento do SUS, ressaltando os impasses provocados pela renúncia fiscal ao setor privado. A segunda parte apresenta a legislação brasileira, que permite a permanência da renúncia fiscal (gasto tributário), especialmente para a saúde. A terceira parte analisa a evolução do Gasto Tributário Social (GTS), em geral, e da saúde, em particular, no período de 2003 a 2012.

\section{A trajetória dos problemas do financiamento do SUS e o crescimento da renúncia fiscal ao setor privado}

O financiamento do SUS transcorreu sobre um longo processo de conflitos e embates. Para começar a entender as diversas tensões nos caminhos institucionais do SUS, ressaltamos a ideia de um duplo movimento pendular e contraditório entre as forças em torno da área da saúde, desde a Constituição, arrastando-se até a aprovação da regulamentação da EC no 29/2000, em dezembro de 2011. É possível dizer que, ao mesmo tempo que se vai desenvolvendo uma saúde universal, sustentada pelo movimento dos defensores do 'princípio da construção da universalidade', agravam-se as finanças do Estado brasileiro, criando limites para o aporte de recursos para a saúde. Assim, as decisões de uma política econômica restritiva/ neoliberal, sustentada por outro movimento, denominado 'princípio da contenção do gasto', mantiveram-se muito firmes durante todos os anos 1990 e 2000, limitando os recursos públicos para assegurar o direito à saúde (MENDES, 2012).

Assim, diante da predominância de políticas macroeconômicas restritivas, adotadas pelos governos FHC e mantidas pelos governos Lula, em consonância com a dominação do capital portador de juros no capitalismo contemporâneo, o trajeto do financiamento do SUS permaneceu sob grande tensão. Não foi à toa que o tema do financiamento não foi retirado da agenda de problemas no âmbito da saúde universal durante todo o período de implementação do direito à saúde, após a Constituição de 1988.

Os conflitos entre os dois princípios comentados não permitiram assegurar uma política de direito universal da saúde. Salienta-se que, entre 1989 e 1993, os embates já eram intensos. Além da não consideração por parte do governo federal dos $30 \%$ da seguridade social, que deveriam ser destinados à saúde, conforme o Ato das Disposições Constitucionais Transitórias, houve certa especialidade das fontes da seguridade social. $\mathrm{O}$ orçamento federal passou a destinar a maior parte dos recursos da Contribuição do Financiamento da Seguridade Social (Cofins) para a saúde, da Contribuição sobre o Lucro para a assistência social e das contribuições de empregados e empregadores para a previdência social, que contou com a exclusividade dessas últimas fontes a partir de 1993. Essa maneira de utilização das fontes de financiamento da seguridade social rompia com o conceito de um orçamento único para as três áreas dela integrantes, desrespeitando a ideia que inspirou sua criação na Constituição de 1988: a visão de lidar com os riscos sociais de forma integrada.

Entre 1994 e 2011, as tensões no financiamento do SUS ganharam proporções ainda mais amplas. Lembremo-nos de modo resumido esse período. Entre os vários constrangimentos, ficaram constatados os seguintes eventos, de acordo com Mendes (2012): 
4 A Lei oㅜ 5.172/66, conhecida como código tributário nacional, estabelece que os impostos não podem ser vinculados a determinadas políticas públicas, diferentemente das contribuições sociais. Sendo assim, a eliminação das contribuições sociais na proposta de reforma tributária do governo Lula tinha um único objetivo: eliminar a vinculação de recursos do governo federal à seguridade social e tornar a desvinculação das receitas permanente. a) a criação da Desvinculação da Receita da União (DRU), em 1994, resultando em uma perda de recursos para a seguridade social de cerca de R $\$ 578$ bilhões, entre 1995 e 2012;

b) a aprovação da Contribuição Provisória sobre Movimentação Financeira (CPMF), em 1997, como fonte exclusiva para a saúde, por um lado, e a retirada de parte das outras fontes desse setor, por outro, não contribuíram para o acréscimo de recursos que se esperava. Essa fonte permaneceu por dez anos, até 2007, quando foi rejeitada no Congresso Nacional;

c) a aprovação da EC n 29, em 2000, vinculando recursos para a saúde, porém, com indefinições sobre quais despesas deveriam ser consideradas como ações e serviços de saúde e o que não poderia ser enquadrado nesse âmbito, além de dispor de método conflitante de cálculo para aplicação dos recursos da União, isto é, o valor apurado no ano anterior corrigido pela variação nominal do Produto Interno Bruto (PIB), e, ainda, de não esclarecer a origem dos recursos no tocante à seguridade social, ignorando o intenso embate por seus recursos;

d) as permanentes investidas da equipe econômica do governo federal contra a vinculação de recursos para a saúde, ao procurar introduzir itens de despesa não considerados gastos em saúde no orçamento do Ministério da Saúde, como o pagamento de juros e da aposentadoria de ex-funcionários desse ministério, além de outros;

e) a pendência da regulamentação da EC $n^{0}$ 29/2000 durante oito anos no Congresso (entre 2003 e 2011), provocando perdas de recursos para o SUS e o enfraquecimento do princípio maior: o direito universal à saúde;

f) a ameaça da proposta de reforma tributária do governo Lula (2008), prejudicando o financiamento da seguridade social, em especial, por meio da extinção das contribuições sociais, tornando todas as fontes agregadas por somente três impostos: Imposto de Renda (IR), Imposto sobre
Produtos Industrializados (IPI) e Imposto do Valor Adicionado Federal (IVA), o que impediria a vinculação de recursos para a seguridade social ${ }^{4}$;

g) a permanência das incertezas do financiamento do SUS com o estabelecimento da regulamentação da EC $\mathrm{n}^{\circ}$ 29/2000, por meio da Lei Complementar $n^{\circ} 141 / 2012$, que não conseguiu resolver o problema da insuficiência de recursos da saúde por parte do governo federal, manteve o método de cálculo conflitante para aplicação dos seus recursos. O método de cálculo para a aplicação da União em ações e serviços de saúde, estabelecido na EC n ${ }^{\circ} 29 / 2000$ e mantido na Lei 141/2012, refere-se ao valor apurado no ano anterior, corrigido pela variação do PIB nominal. Essa base de aplicação difere de estados e municípios, na medida em que, para esses entes, o cálculo incide sobre os recursos próprios arrecadados. A EC n ${ }^{0} 29 / 2000$ estabeleceu que estados devessem alocar $12 \%$, no mínimo, da receita de impostos, compreendidas as transferências constitucionais, e municípios direcionassem $15 \%$, no mínimo, da mesma base de cálculo. A EC no $29 / 2000$, para a União, não explicita a origem dos recursos e foi omissa com relação à Seguridade Social, como se não houvesse conflito por seus recursos.

Nesse cenário, as tensões no financiamento do SUS não foram poucas. Em realidade, mantiveram-se constantes e cada vez com maior intensidade no âmbito do governo federal. Constatou-se que as disputas por recursos estiveram presentes antes e após o estabelecimento da $\mathrm{EC} \mathrm{n}^{\circ} 29 / 2000$, isto é, durante as resistências dos governos FHC, nos anos 1990, por assegurarem recursos compatíveis à universalidade, e houve ausência dos governos Lula, entre 2003 e 2010, em elevar a saúde pública à condição de política prioritária, postergando qualquer decisão mais enfática sobre o desempenho do governo federal na aplicação de recursos em ações e serviços de saúde. 
Para ilustrar essas afirmações, ressalta-se que, em 1995, foi gasto pelo governo federal, na proporção do $\mathrm{PIB}$, cerca de $1,7 \% \mathrm{com}$ ações e serviços de saúde. Passados quinze anos (2012), essa proporção praticamente se manteve, ou seja, os governos Lula pouco fizeram para modificá-la (MENDES, 2012).

\section{O aumento da renúncia fiscal (gasto tributário) de saúde}

Considera-se importante, também, na avaliação do gasto público federal, o incentivo concedido pelo governo à saúde privada. O total desses benefícios tributários cresce de forma considerável. Registre-se: $\mathrm{R} \$ 3,67$ bilhões, em 2003; passando para $\mathrm{R} \$ 8,70$ bilhões, em 2006; R $\$ 15,85$ bilhões, em 2009; e, por fim, $R \$ 19,98$, em $2012^{5}$.

Para se ter uma ideia do detalhamento desses benefícios, o gráfico 1 apresenta sua evolução, entre 2007 e 2011, denominada, então, como renúncia fiscal na saúde, destacando os recursos projetados e os efetivamente executados pelo orçamento da União.

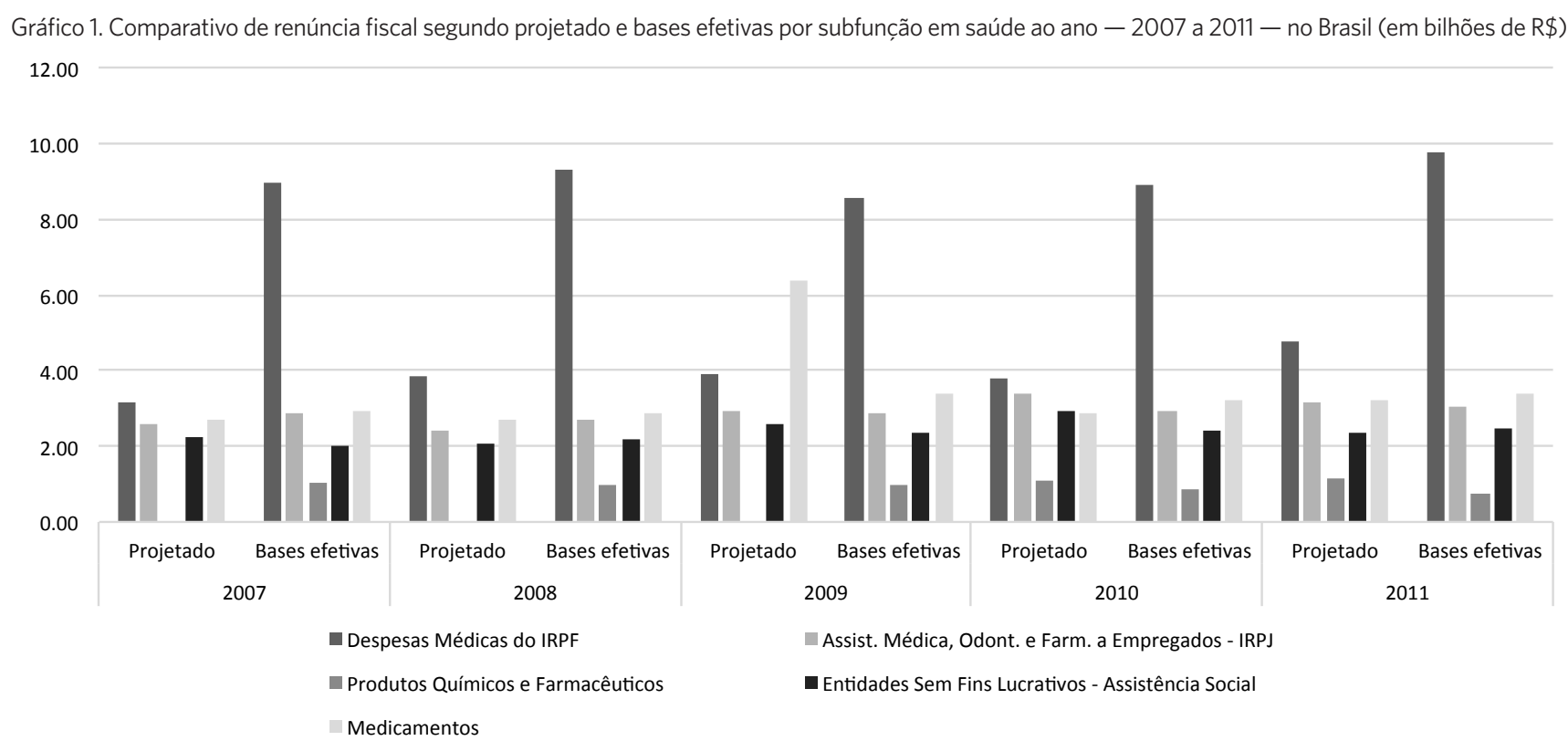

Fonte: Elaboração própria

Observa-se que, entre 2007 e 2011, as bases projetadas para a renúncia fiscal foram menores que os dispêndios efetivamente gastos, particularmente, no tocante às despesas médicas do Imposto de Renda Pessoa Física (IRPF) (gráfico 1). É digno de nota que a sua magnitude de recursos é bem superior às demais subfunções - Medicamentos; Assistência Médica Odontológica e Farmacêutica; Entidades
Sem Fins Lucrativos - Assistência Social; e Produtos Químicos e Farmacêuticos - em todo o período analisado. Cabe ressaltar que a Receita Federal não disponibiliza as informações detalhadas dos componentes das subfunções, o que impede uma análise de qualquer particularidade dos mesmos.

Chama à atenção a efetiva utilização desse mecanismo de renúncia fiscal por parte da sociedade brasileira. Sabe-se que, no Brasil, a

\footnotetext{
5 Dados extraídos da SRF - Previsões PLOA Relatórios de renúncia que acompanharam os Projetos de Lei Orçamentária Anual. Disponível em: <http:// www.receita.fazenda. gov.br/Arrecadacao/ BenTributarios/ DemonsBenefTributario. htm>.
} 
6 Lei no 9.250, de 26 de dezembro de 1995, art. 8 ㅇ, inciso II, "b", com redação dada pela Lei no 11.482, 31 de maio de 2007, alterada pela Lei $n^{\circ}$ 12.469 , de 26 de agosto de 2011, art. 3; Decreto no 3.000, de 26 de março de 1999 - Regulamento do Imposto sobre a Renda (RIR/1999), art. 81; Instrução Normativa SRF no 15 , de 6 de fevereiro de 2001, art. 39

7 Em Portugal, desde 2006 foi estabelecido um limite financeiro para a renúncia fiscal de saúde no Imposto de Renda Pessoa Física. Ver Pereira (2006) legislação permite que os abatimentos junto à declaração de IRPF, com despesas médicas privadas, não dispõem de limites, diferentemente da área da educação - limite anual individual de $\mathrm{R} \$ 3.091,35$ (ano-calendário de $2012)^{6}$. Sem dúvida, a possibilidade de estabelecimento de limites para a área da saúde deve ser um foco de amplo debate no interior desse complexo tema de incentivos ao subsistema privado de saúde no País 7 .

De foma geral, Ocké-Reis e Santos (2011) assinalam dois argumentos que devem ser ponderados na discussão sobre a renúncia fiscal em saúde, quanto ao problema do financiamento do nosso sistema universal. Em primeiro lugar, pode-se considerar que a renúncia fiscal contribui para o aumento da oferta hospitalar privada e, também, para a expansão do mercado de planos de saúde, por meio de apoio do Estado, em prejuízo ao financiamento do SUS e, consequentemente, à garantia do direito universal à saúde.

Esse argumento pode ser associado à força que o capital portador de juros (capital financeiro) impõe ao Estado para assegurar seus espaços de valorização (MENDES, 2012). Sabe-se que grande parte dos planos de saúde no País vem se enquadrando ao processo de financeirização, acirrando a temática da perversa relação público-privada na saúde, tão discutida nas últimas décadas (BAHIA, 2010). Ocké-Reis e Santos (2011) comentam que, justamente após a década de 1980, no momento em que o capital portador de juros retornou soberano, a classe média começou a consumir planos de saúde, e os trabalhadores passaram a demandá-los, como um acréscimo de salário de suas empresas.

Em segundo lugar, esses autores assinalam que, em razão de restrição orçamentária do orçamento público e da crise crônica de financiamento do SUS, deve-se criticar o subsídio implícito na renúncia, em decorrência de seu caráter regressivo em favor aos grupos sociais com maior capacidade de receita e, portanto, de gasto. Isso porque os indivíduos que se situam no topo da distribuição de renda, ao abaterem seus gastos no Imposto de Renda, receberiam, em termos per capita, uma quantidade maior de recursos.

Sob o aspecto da saúde financeira do SUS, a solução seria, de um lado, eliminar a renúncia, uma vez que o sistema público deveria cobrir as necessidades de todos os brasileiros. De outro lado, parte dos recursos poderia ser revertida para o SUS, contribuindo para a melhoria das pressões existentes sobre o acesso e a utilização do sistema.

Acreditamos que os argumentos apresentados por Ocké-Reis e Santos (2011) mostram um dos grandes embates em torno da renúncia fiscal na saúde. Sem dúvida, essa discussão remete à problemática relação entre o mercado privado e o padrão de financiamento da saúde universal, e, ao mesmo tempo, às suas consequências com relação à temática da equidade, tão importante para a sobrevivência do SUS.

Assim, concordamos com esses autores quando afirmam que:

[...] o aumento da participação do setor público no financiamento da saúde pública se contrapõe à subvenção estatal ao setor privado de saúde, fator gerador de iniquidades, resultando em um acesso fragmentado e desigual dos cidadãos brasileiros ao sistema de saúde. (OCKÉ-REIS; SANTOS, 2011, P. 15).

\section{A legislação da renúncia fiscal (gasto tributário) em saúde}

O movimento de ampliação dos gastos tributários (renúncia fiscal) se apoia em aspectos jurídico-legais há muitos anos no País, principalmente, a partir da década de 1990, com maior presença nas decisões de política econômica, voltadas para assegurar o 'princípio da contenção do gasto'.

Nesse sentido, a legislação sobre o Imposto de Renda apresenta a questão dos 
gastos tributários se concentrando em duas principais leis: a Lei $\mathrm{n}^{0} 9.250$, de 26 de dezembro de 1995, que altera a legislação do Imposto de Renda das pessoas físicas e dá outras providências; e a Lei n ${ }^{\circ} 9.249$, de 26 de dezembro de 1995, que modifica a legislação do Imposto de Renda das Pessoas Jurídicas (IRPJ), bem como da contribuição social sobre o lucro líquido (BRASIL, 1995A; 1995B).

Para a identificação do setor saúde, nesse contexto de isenções tributárias, torna-se importante mencionar o artigo $8^{\circ}$ da Lei ${ }^{\circ}$ 9.250, que estabelece que "a base de cálculo do imposto devido ao ano-calendário será a diferença entre as somas das deduções relativas", que incluem os seguintes pagamentos: pagamentos efetuados, no ano-calendário, a médicos, dentistas, psicólogos, fisioterapeutas, fonoaudiólogos, terapeutas ocupacionais e hospitais, bem como as despesas com exames laboratoriais, serviços radiológicos, aparelhos ortopédicos e próteses ortopédicas e dentárias (BRASIL, 1995A).

Ainda no $\subseteq 2^{\circ}$ do mesmo artigo, soma-se ao disposto, na alínea, mais dois itens:

I - aplica-se, também, aos pagamentos efetuados a empresas domiciliadas no País, destinados à cobertura de despesas com hospitalização, médicas e odontológicas, bem como a entidades que assegurem direito de atendimento ou ressarcimento de despesas da mesma natureza;

II - restringe-se aos pagamentos efetuados pelo contribuinte, relativos ao próprio tratamento e ao de seus dependentes. (BRASIL, 1995A).

De forma a ampliar os critérios de isenções relativas aos gastos com saúde por pessoas jurídicas do item I, descritos no parágrafo anterior, apresenta-se a Lei $\mathrm{n}^{\circ}$ 9.249, com destaque para o artigo 13, item V:

Para efeito de apuração do lucro real e da base de cálculo da contribuição social sobre o lucro líquido (CSLL), são vedadas as seguintes deduções, independentemente do disposto no art. 47 da Lei $n$ ㅇ 4.506, de 30 de novembro de 1964: [...].

V - das contribuições não compulsórias, exceto as destinadas a custear seguros e planos de saúde, e benefícios complementares assemelhados aos da previdência social, instituídos em favor dos empregados e dirigentes da pessoa jurídica. (BRASIL, 1995A).

Temos, então, que, além da redução dos valores pagos de Imposto de Renda, reduz-se também o valor da CSLL que as pessoas jurídicas devem realizar. Importante lembrar que a CSLL é uma das fontes de recursos que compõem o Orçamento da Seguridade Social (OSS), que inclui as áreas de previdência, saúde e assistência social.

No tocante à legislação para Entidades Sem Fins Lucrativos - Assistência Social, destaca-se a Lei no 9.532, de 10 de dezembro de 1997, que altera a legislação tributária federal e dá outras providências. Nessa lei, no artigo $12^{\circ}$, indica-se que ficam isentas as instituições:

De educação ou de assistência social que preste os serviços para os quais houver sido instituída e os coloque à disposição da população em geral, em caráter complementar às atividades do Estado, sem fins lucrativos. (BRASIL, 1997).

Ainda nesse artigo, no $₫ 2^{\circ}$, item $b$, as instituições que gozam de tal isenção devem "aplicar integralmente seus recursos na manutenção e desenvolvimento dos seus objetivos sociais" (BRASIL, 1997). Em complementação à Lei no 9.532 , foram, ainda, aprovadas a Lei $\mathrm{n}^{\circ} 12.101$, de 27 de novembro de 2009, sendo, ainda, atualizada pelo Decreto n..$^{\circ}$ 7.237, de 20 de julho de 2010.

Para as isenções ligadas aos itens Produtos Químicos e Farmacêuticos, as leis específicas foram relacionadas segundo o ano de aprovação e apresentam certa continuidade de uma política de importação de produtos considerados de base para a indústria farmacêutica. 
8 Para o entendimento das exigências previstas pela LRF, ver Mendes e Moreira (2001).
A Lei $\mathrm{n}^{\circ} 10.637$, de 30 de dezembro de 2002, em seu Art. $2^{\circ} \& 3^{\circ}$, apresenta:

Fica o Poder Executivo autorizado a reduzir a 0 (zero) e a restabelecer a alíquota incidente sobre receita bruta decorrente da venda de produtos químicos e farmacêuticos, classificados nos Capítulos 29 e 30 da TIPI, sobre produtos destinados ao uso em hospitais, clínicas e consultórios médicos e odontológicos, campanhas de saúde realizadas pelo poder público, laboratório de anatomia patológica, citológica ou de análises clínicas (BRASIL, 2002).

Em consonância com essa lei, são aprovadas, ainda, a Lei ${ }^{\circ} 10.833$, de 29 de dezembro de 2003 , e Lei $\mathrm{n}^{\circ} 10.865$, de 30 de abril de 2004, mantendo a situação de isenção já descrita, e, por fim, no Decreto $n^{0} 6.426$, de 7 de abril de 2008, expande-se a operação de importação dos produtos, já descritos no parágrafo anterior, por meio do Anexo III desse decreto.

Por fim, no tocante à legislação sobre isenções de medicamentos, merece menção a Lei $\mathrm{n}^{\circ} 10.147$, de 21 de dezembro de 2000, e, em atualização, a Lei n ${ }^{\circ} 10.548$, de 13 de novembro de 2002, ambas reduzindo a carga de PIS e Cofins para pessoas jurídicas que procedam à industrialização ou à importação dos produtos farmacêuticos que

cumpram a sistemática estabelecida pela Câmara de Medicamentos para utilização do crédito presumido, na forma determinada pela Lei no 10.213, de 27 de março de 2001. (BRASIL, 2001).

Tendo em vista as principais leis aqui descritas, pode-se afirmar que os gastos tributários sociais (em especial, os da área da saúde) estão largamente respaldados por arcabouço jurídico-legal, possibilitando a sua sustentabilidade institucional, especialmente a partir dos anos 2000, com o advento da Lei de Responsabilidade Fiscal, que permite sua existência ${ }^{8}$. A Lei de Responsabilidade Fiscal (LRF), Lei
Complementar $\mathrm{n}^{0} 101 / 2000$, não proíbe a renúncia de receita nem dispensa a lei para a concessão ou ampliação de incentivos ou benefícios, apenas requer novas exigências para a renúncia de receita, que devem ser observadas antes da elaboração da lei específica, verificando o atendimento às condições do disposto no artigo 14 dessa Lei de Responsabilidade Fiscal. A rigor, o possível questionamento à sua expansão, provocando uma frágil situação da capacidade do gasto do Estado junto às políticas públicas, deve ter em conta o necessário enfrentamento à revogação de ampla legislação.

\section{A evolução dos gastos tributários sociais e da saúde de 2003 a 2012}

\section{Orientações metodológicas para a análise dos gastos tributários}

Antes de se promover à análise dos gastos tributários sociais e da saúde, entende-se ser fundamental apreender a abrangência conceitual desses gastos específicos. Alvarenga $(2012$, P. 2) argumenta que "não há um conceito bem definido na literatura sobre o que são gastos tributários, permitindo aos diversos países defini-los de forma distinta". A autora ainda afirma que "não há um conceito definido oficialmente acerca de quais gastos tributários correspondem a gastos sociais". Porém, no Demonstrativo dos Gastos Tributários (BRASIL, 2011), esse conceito parece ser tratado de forma clara:

São explicitados na norma que referencia o tributo, constituindo-se uma exceção ao sistema tributário de referência, reduzindo a arrecadação potencial e, consequentemente, aumentando a disponibilidade econômica do contribuinte. Têm caráter compensatório, quando o governo não atende adequadamente a população dos serviços 
de sua responsabilidade, ou têm caráter incentivador, quando o governo tem a intenção de desenvolver determinado setor ou região. (BRASIL, 2011, P. 11).

O documento da Receita Federal segue indicando que:

Em complemento ao conceito acima, passou- se a utilizar a regra dos dois passos para se identificar os gastos tributários do conjunto de desonerações do sistema tributário: determinar todas as desonerações tributárias tomando como base um sistema tributário de referência; e avaliar, utilizando os critérios definidos no conceito acima, quais as desonerações são gastos indiretos passíveis de serem substituídas por gastos diretos, vinculados a programas de governo. (BRASIL, 2011, P. 12).

Tendo uma definição inicial por parte da Receita Federal, cabe ressaltar a dificuldade de acompanhamento dos gastos tributários efetivos. Em estudo realizado em 2011 pela Receita, as informações correspondem às estimativas realizadas para o orçamento do próximo ano, e diversos itens não possuem valores disponíveis, prejudicando uma real análise sobre as execuções desses gastos tributários.

Ao se considerar que a finalidade dessas isenções tributárias seja compensar gastos realizados pelos contribuintes com serviços não atendidos pelo governo e, ao mesmo tempo, incentivar determinado setor da economia, é provável que haja uma substituição das políticas públicas, no caso, a saúde pública, por serviços prestados por terceiros, que, diferentemente do objetivo do Estado, de garantir o direito à saúde, tenha outra finalidade: a valorização do capital, entendendo saúde como mercadoria.

Nessa perspectiva, Martins e Martins (2012) argumentam o real sentido do movimento do capital com relação à apropriação do setor saúde, ao esclarecerem que:
Em face das nossas reflexões, e devido o esgotamento do antigo padrão de acumulação de capital, principalmente no setor industrial, para a extração de valor excedente, compreendemos que os impactos causados pelas transformações no mundo do trabalho vêm atingindo de forma rápida (e negativa) as sociedades. Trata-se de transformações provocadas pela diminuição da taxa de lucro global do capital nas diversas esferas da produção ou, em outras palavras, devido o esgotamento do antigo padrão de acumulação de capital, principalmente no setor industrial, para a extração de valor excedente. Compreendemos que está em jogo a necessidade estrutural do capital em expandir-se para outras áreas da economia, sobretudo para o setor de serviços, no qual se inclui o setor saúde transformando-o em importante campo para o processo de valorização do capital. (MARTINS; MARTINS, 2012, P. 7).

Essa afirmação apresentada nos convoca para uma necessária análise da dimensão dos dados econômico-financeiros sobre os gastos públicos, e, nestes, especialmente os tributários em saúde. Torna-se necessário desenvolver aprofundamento e acompanhamento dessa possível mudança do direito à saúde para uma mercantilização desta.

Para a realização da análise dos gastos tributários sociais e da saúde, buscaram-se as fontes da Secretaria do Tesouro Nacional, da Receita Federal e da Agência Nacional de Saúde Suplementar (ANS), do Datasus/Ministério da Saúde. O período de análise compreende os anos de 2003 a 2012. Todos os valores financeiros foram corrigidos segundo o Índice Geral de Preços Disponibilidade Interna (IGP-DI), com mês de referência de dezembro de 2012.

Ainda cabe mencionar que os valores correspondentes aos gastos tributários são projeções e estimativas em bases efetivas apresentadas anualmente nos Demonstrativos dos Gastos Tributários. Utilizou-se como caracterizador de GTS o 
estudo realizado por Alvarenga (2012), efetuando-se alguns recortes para uma análise mais ampla das funções orçamentárias (maior agregação do nível das despesas).

A autora apresenta a definição baseada em alguns estudos que resultam nas seguintes classificações que compõem o GTS: Alimentação e Nutrição; Assistência Social; Ciência e Tecnologia; Cultura; Educação; Emprego e Defesa do Trabalhador; Entidades sem Fins Lucrativos; Habitação e Urbanismo; Previdência Social; Saúde. Para este artigo, os campos da Previdência Social, Emprego, Defesa do Trabalho e Alimentação e Nutrição foram agregados na função Trabalho. Incluíram-se, ainda, as funções: Direitos da Cidadania, Gestão Ambiental e Saneamento. O item Entidades Sem Fins Lucrativos não foi considerado por estar distribuído nas funções em que as empresas prestam serviços (saúde, educação, cultura etc.).

Concordamos com Alvarenga (2012, P. 6) quando diz que

embora a classificação ainda seja caracterizada por um alto nível de subjetividade, isso não deve ser empecilho para a análise e detaIhamento dos valores apresentados nos Demonstrativos anuais.

De outro modo, a autora insiste em afirmar que "o debate deve ser aprofundado cada vez mais, aumentando o número de informações disponíveis sobre o assunto".

\section{Resultados da análise dos gastos tributários}

Ao se analisar a participação das principais funções no total dos gastos tributários, entre 2003 e 2012, constata-se que a Saúde é a terceira maior função, sendo inferior apenas às funções de 'Comércio e Serviço' e 'Indústria', respectivamente (gráfico 2).

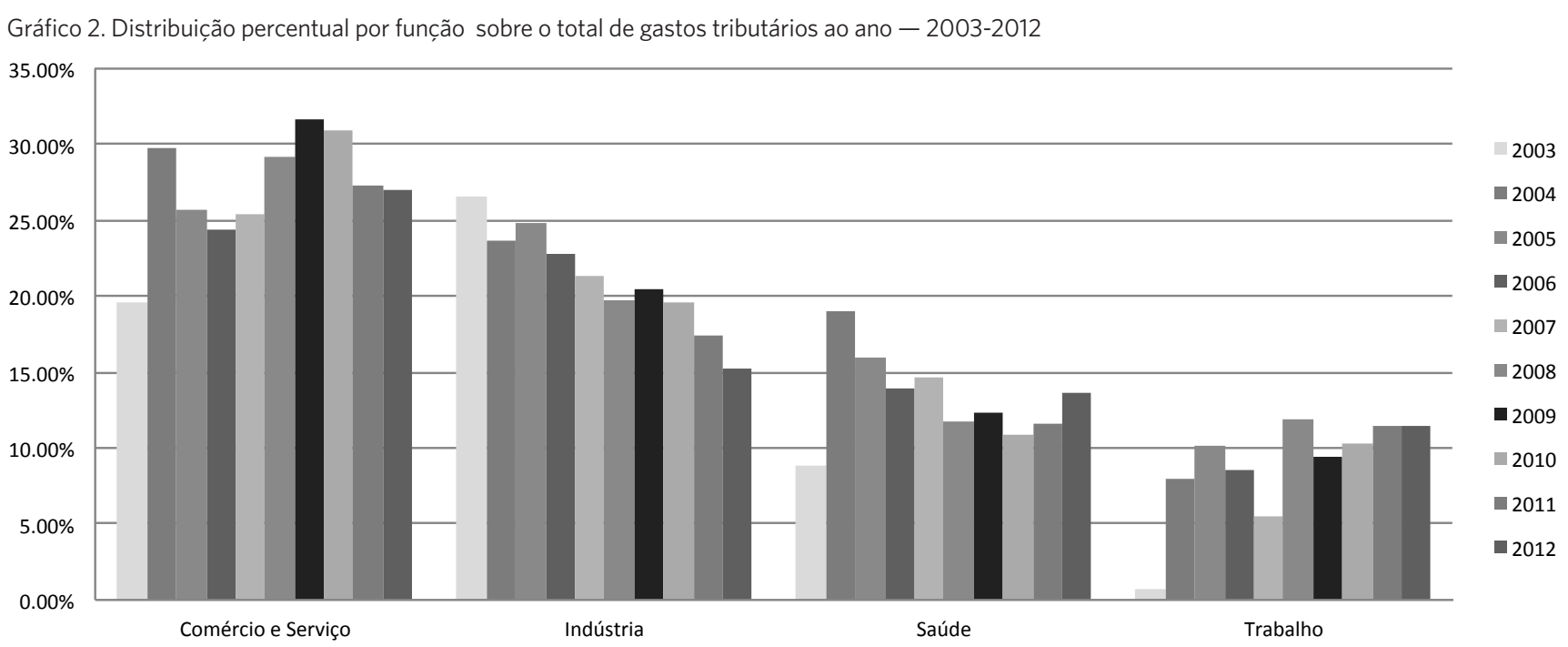

Para se ter uma ideia do desempenho da distribuição do total do gasto tributário por funções, em 2012, a Saúde corresponde à terceira posição, com 13,6\%, logo após a função Indústria, com 15,19\%, e 'Comércio e Serviço', com $27,6 \%$.
Quando se destacam as funções ligadas ao GTS para 2012, tem-se a Saúde como maior percentual desses gastos (30,5\%), seguida do Trabalho (25,7\%), ficando bem superior à Assistência Social (10,5\%), à Educação $(10,8 \%)$ e às outras funções 
(22,6\%) (Dados da Receita Federal do Brasil $\left.{ }^{9}\right)$.

Ao se analisar a participação das modalidades de gastos tributários sobre o total de gastos da função Saúde, observa-se que as 'Despesas Médicas do IRPF' e a 'Assistência Médica, Odontológica e Farmacêutica a Empregados - IRPJ' são as principais. Juntas, somaram, em 2012, $64,80 \%$, com uma mediana, no período analisado, de $34,66 \%$ e $18,54 \%$, respectivamente (gráfico 3).

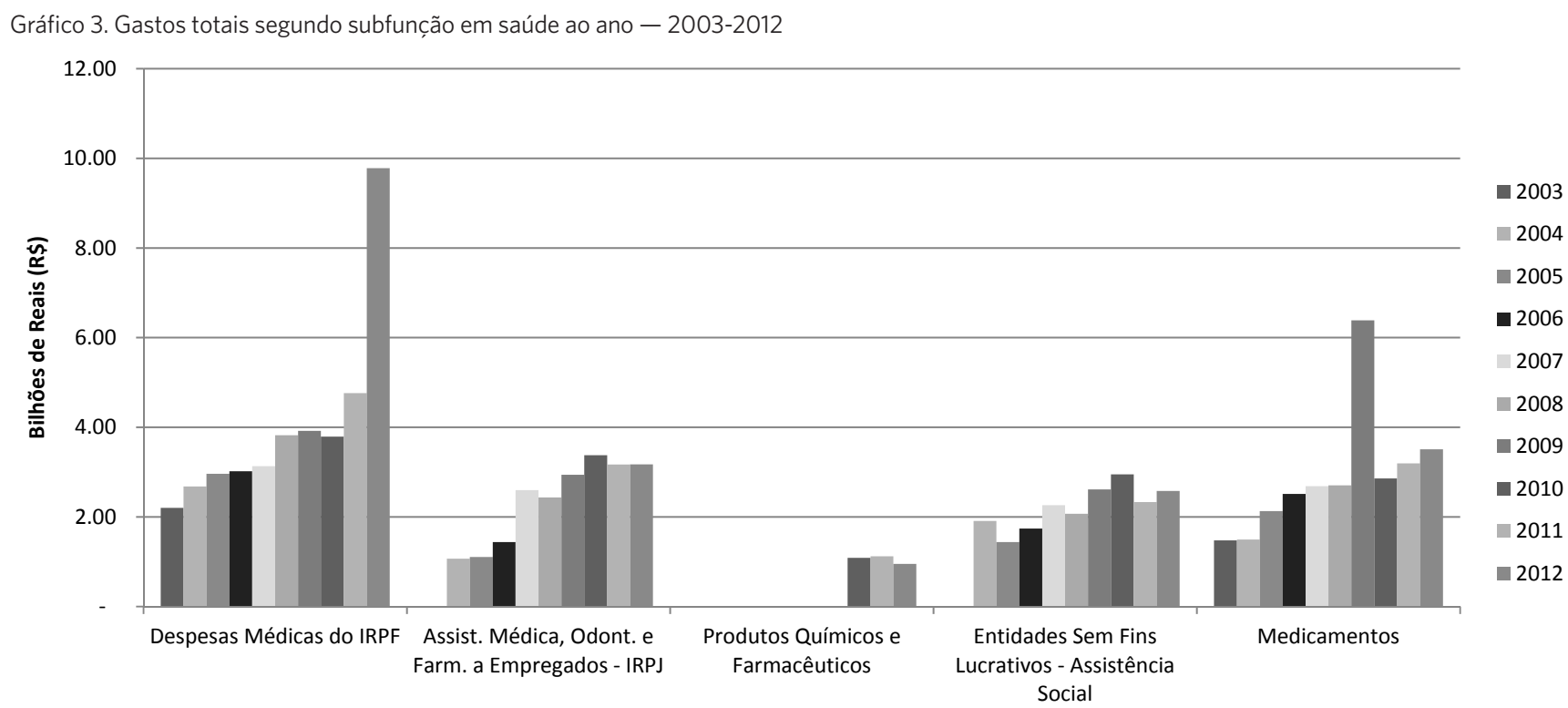

Fonte: Elaboração própria

Por sua vez, quando se analisa a participação da população coberta por planos de saúde (Assistência Médica) no Brasil, constata-se o pequeno patamar de $34,2 \%$, em $2012^{10}$. A grande maioria da população brasileira não dispõe de planos, ficando sob a cobertura do SUS, que, como se verifica, fica prejudicado na sua capacidade de financiamento, entre vários aspectos destacados na primeira seção ou deste artigo, além de o Estado subsidiar a população que dispõe de planos, via renúncia fiscal (gasto tributário). De acordo com dados da ANS11, ao se fazer uma distinção entre os tipos de contratação desses planos de saúde (Assistência Médica), verifica-se que, entre 2003 e 2012, o 'coletivo empresarial' apresenta a maior participação no total desses tipos de contratação e também o maior crescimento no período, passando de $36,40 \%$, em 2003, para 62,69\%, em 2012 (gráfico 4).

\footnotetext{
9 Disponível em: $<$ http://www.receita. fazenda.gov.br/publico/ estudotributario/ benstributarios/2012/ dgt2012.pdf>

10 Dados extraídos da ANS. Disponível em: <http:// www.ans.gov.br/>.

11 Dados extraídos da ANS. Disponível em: <http:// www.ans.gov.br/>.
} 


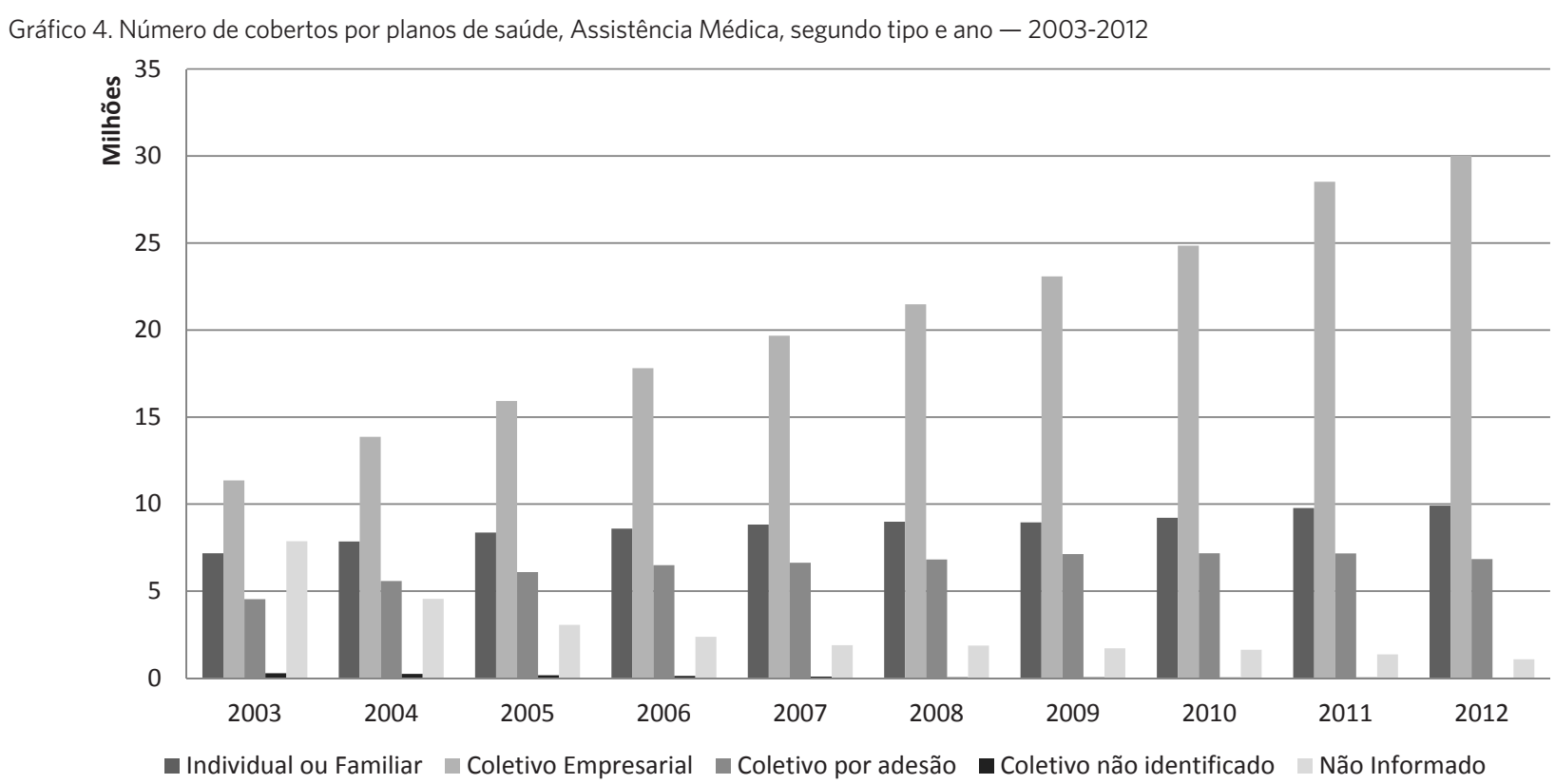

Fonte: Elaboração própria

12 Para uma discussão sobre o processo de desoneração da folha de pagamento de setores da economia brasileira realizado pela presidente Dilma, onerando o financiamento da seguridade social, ver Marques e Mendes (2013).
Esse importante quadro da renúncia fiscal para o consumo de planos de saúde no Brasil deve ser contraposto ao desempenho de seu mercado entre 2003 e 2011. Segundo Ocké-Reis (2013), verifica-se que o faturamento do mercado dobrou, e seu lucro líquido teve um incremento mais de duas vezes e meia acima da inflação.

Por fim, merece comentar a relação entre os gastos tributários na função Saúde e as despesas orçamentárias da União na função Saúde. Depreende-se que, ao longo do período de 2003 a 2012, tal relação teve um aumento considerável, passando de 7,78\%, em 2003, para 24,96\%, em 2012 (gráfico 5). Entre 2009 e 2011, observa-se uma queda dessa relação em virtude das desonerações tributárias à contribuição previdenciária de setores da economia brasileira realizadas pela presidente Dilma, o que prejudicou o financiamento da seguridade social (a previdência social integra esse orçamento ${ }^{12}$ ). Já a partir de 2011, observa-se o retorno ao crescimento.

Gráfico 5. Despesas da União e gastos tributários na função Saúde ao ano - 2003-2012

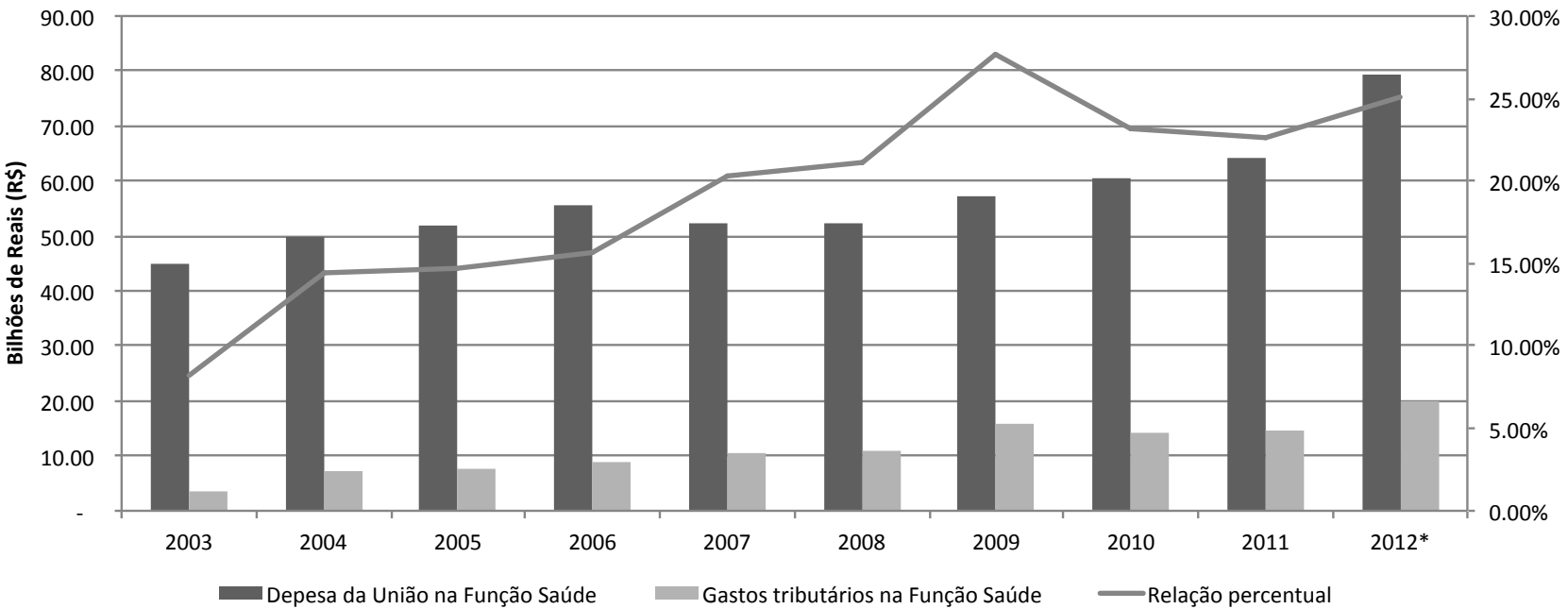




\section{Considerações finais}

Desde sua implantação, o SUS enfrenta problemas de financiamento. Ao longo de sua história, os recursos públicos envolvidos sempre foram insuficientes para garantir uma saúde pública universal. Não resta dúvida de que, decorrente dessa situação, há uma necessidade premente de aumentar o volume de recursos para reduzir as desigualdades regionais no acesso aos serviços de saúde, bem como para melhorar a qualidade da atenção básica à saúde, levando-a para toda a população, expandindo e aparelhando a rede pública.

Para enfrentar essa insuficiência de recursos públicos para a saúde dos brasileiros, deveríamos nos preocupar com a persistência dos incentivos fiscais ao setor privado da saúde, o que se traduz no subsídio implícito nas deduções do Imposto de Renda das despesas com Planos Privados de Saúde e/ ou com despesas particulares com médicos, hospitais e exames. Como apresentado neste trabalho, o total dos benefícios tributários concedidos à saúde privada, denominado renúncia fiscal (gasto tributário) em saúde, vem crescendo de forma considerável ao longo dos últimos anos, atingindo o patamar de $\mathrm{R} \$ 19,98$ bilhões em 2012. Tal recurso, se destinado ao SUS, contribuiria significativamente para enfrentar o subfinanciamento desse sistema.

A rigor, os gastos tributários em saúde vêm assumindo papel de destaque, principalmente quando se analisa o percentual próximo ao da Indústria. Com a possibilidade de pessoas físicas e, principalmente, jurídicas terem parte de seus pagamentos dos Impostos de Renda reduzidos, pelo consumo de planos de saúde ou compra direta de serviços, sem uma margem máxima de desconto, há possibilidade de um crescimento desenfreado das isenções tributárias nessa função.

$\mathrm{O}$ que vem à tona é um direcionamento da saúde pública para uma mercantilização, de direito social a produto, provocando um ocultamento enquanto política social, que vise à universalidade, à igualdade e à equidade.

As entidades envolvidas com o compromisso da construção do SUS devem exigir que sejam controlados esses subsídios à saúde privada, que não só comprometem recursos que poderiam ser dirigidos à saúde pública como impedem que o SUS seja assumido como sendo de toda a população brasileira.

\section{Referências}

AGÊNCIA NACIONAL DE SAÚDE SUPLETMENTAR. Disponível em: <http://www.ans.gov.br/>. Acesso em: 10 out. 2014.

ALVARENGA, L. V. H. Gastos Tributários Sociais - Como estamos? In: ENCONTRO NACIONAL DE ECONOMIA POLÍTICA, 17., Anais... Porto Alegre: UFRGS, 2012.

BAHIA, L. A privatização no sistema de saúde brasileiro nos anos 2000: tendências e justificação. In: SANTOS, N. R.; AMARANTE, P. D. C. (Org.).
Gestão pública e relação público privado na saúde. Rio de Janeiro: Cebes, 2010. p. 115-128. Disponível em : <http://www.cebes.org.br/media/File/ Gest\%E3o\%20P\%FAblica\%20e\%20Rela\%E7\%E3o\%20 P\%FAblico\%20e\%20Privado\%20na\%20Sa\%FAde.pdf>. Acesso em: 12 jun. 2011.

BANCO CENTRAL DO BRASIL. Disponível em: <www.bcb.gov.br>. Acesso em:10 out. 2014.

BRASIL. Ministério da Saúde. Disponível em: <http:// portalsaude.saude.gov.br/>. Acesso em: 10 out. 2014. 
Lei $\mathrm{n}^{\circ} 9.249$, de 26 de dezembro de 1995. Altera a legislação do imposto de renda das pessoas jurídicas, bem como da contribuição social sobre o lucro líquido, e dá outras providências. Diário Oficial [da] União, Brasília, DF, 1995a. Disponível em: <http://www.planalto.gov.br/CCIVIL_03/leis/L9249.htm>. Acesso em: 10 out. 2014

Lei $\mathrm{n}^{\circ} 9.250$, de 26 de dezembro de 1995. Altera a legislação do imposto de renda das pessoas físicas e dá outras providências Diário Oficial [da] União, Brasília, DF, 1995b. Disponível em: <http://www.planalto.gov.br/ccivil_03/leis/L9250.htm>. Acesso em: 10 out. 2014.

Lei $\mathrm{n}^{\circ}$ 9.532, de 10 de dezembro de 1997. Altera a legislação tributária federal e dá outras providências Diário Oficial [da] União, Brasília, DF, 1997. Disponível em: <http://www.planalto.gov.br/ccivil_03/leis/19532. htm>. Acesso em: 10 out. 2014.

Lei n. ${ }^{\circ}$ 10.213, de 27 de março de 2001. Define normas de regulação para o setor de medicamentos, institui a Fórmula Paramétrica de Reajuste de Preços de Medicamentos - FPR, cria a Câmara de Medicamentos e dá outras providências. Diário Oficial [da] União, Brasília, DF, 2001. Disponível em: <http:// www2.camara.leg.br/legin/fed/lei/2001/lei-10213-27-marco-2001-367183-publicacaooriginal-1-pl.html>. Acesso em: 11 out. 2014.

Lei $\mathrm{n}^{\circ} 10.637$, de 30 de dezembro de 2002.

Dispõe sobre a não cumulatividade na cobrança da contribuição para os Programas de Integração Social (PIS) e de Formação do Patrimônio do Servidor Público (Pasep), nos casos que especifica; sobre o pagamento e o parcelamento de débitos tributários federais, a compensação de créditos fiscais, a declaração de inaptidão de inscrição de pessoas jurídicas, a legislação aduaneira, e dá outras providências. Diário Oficial [da] União, Brasília, DF, 2002. Disponível em: <http:// www.planalto.gov.br/ccivil_03/leis/2002/110637.htm>. Acesso em: 11 out. 2014.

Ministério da Fazenda. Receita Federal do

Brasil. Demonstrativo dos Gastos Governamentais

Indiretos de Natureza Tributária - 2012 (Gastos
Tributários). Brasília, DF: Ministério da Fazenda, 2011

DAIN, S.; QUADROS, W. L.; CAVALCANTI, C. E. G. Renúncia fiscal e assistência médica suplementar. In: BRASIL. Ministério da Saúde. Agência Nacional de Saúde Suplementar. Regulação e saúde: estrutura, evolução e perspectivas da assistência médica Suplementar . Rio de Janeiro: Agência Nacional de Saúde Suplementar, 2002. p. 223-244.

MARQUES, R. M.; MENDES, A. A proteção social no capitalismo contemporâneo em crise. Argumentum,Vitória, v. 5, n. 1, p. 135-163, 2013.

MARTINS, P. P. S. MARTINS, L. S. A reestruturação produtiva do trabalho e o processo de mercantilização da saúde no Brasil. In: COLÓQUIO INTERNACIONAL MARX ENGELS, 7., Anais... Campinas: Cemarx, 2012.

MENDES, A. Tempos turbulentos da saúde pública brasileira: os impasses do financiamento no capitalismo financeirizado. São Paulo: Hucitec, 2012.

MENDES, A.; MOREIRA, M. (Org.). Comentários à Lei de Responsabilidade na Gestão Fiscal. São Paulo: Cepam, 2001.

PEREIRA, J. Deduções fiscais e despesas de saúde. In: CONGRESSO DE ECONOMIA DA SAÚDE DA AMÉRICA LATINA E CARIBE, 2., Anais...Buenos Aires: Abres, 2006.

OCKÉ-REIS, C. O. Mensuração dos gastos tributários: o caso dos planos de saúde - 2003-2011. Brasília, DF: Ipea, 2013. (Nota Técnica, 5).

OCKÉ-REIS, C. O.; SANTOS, F. P. Mensuração dos Gastos Tributários em saúde - 2003-2006. Brasília, DF: Instituto de Pesquisa Econômica Aplicada; 2011. (Texto para Discussão, n. 1637). Disponível em: <http:// www.ipea.gov.br/agencia/images/stories/PDFs/TDs/ td_1637.pdf>. Acesso em: 5 fev. 2012.

SAYD, P. D. Renúncia fiscal e equidade na distribuição de recursos para a saúde. Dissertação (Mestrado) Fundação Oswaldo Cruz, Escola Nacional de Saúde Pública, Rio de Janeiro, 2003. 
SERVO, L. M. S. et al. Financiamento e gasto público de saúde: histórico e tendências. In: MELAMED, C.; PIOLA, S. F. (Org). Políticas públicas e financiamento federal do Sistema Único de Saúde. Brasília, DF: Ipea; 2011. Disponível em: <http://www.ipea.gov.br/portal/ images/stories/PDFs/livros/livro_politpublicas_saude. pdf>. Acesso em: 13 jan. 2012.

WORLD HEALTH STATISTICS (WHO). World Health Statistics 2012. Genebra: World Health Organization,
2012. Disponível em: <http://www.who.int/healthinfo/ EN_WHS2012_Full.pdf>. Acesso em: 12 out. 2014.

Recebido para publicação em outubro de 2014

Versão final em feveiro de 2015

Conflito de interesses: inexistente

Suporte financeiro: não houve 